\title{
The Acceptance Factors and Effectiveness of MOOC in the Blended Learning of Computer Architecture and Organization Course
}

\author{
Salman Firdaus Sidek*, Maizatul Hayati Mohamad Yatim, Shamsul Arrieya Ariffin, Ahmad Nurzid \\ Universiti Pendidikan Sultan Idris, Perak, Malaysia
}

Received October 9, 2019; Revised November 22, 2019; Accepted December 26, 2019

Copyright $\odot 2020$ by authors, all rights reserved. Authors agree that this article remains permanently open access under the terms of the Creative Commons Attribution License 4.0 International License

\begin{abstract}
Purpose of the study: This study examined the effectiveness of MOOC in the blended learning of Computer Architecture and Organization course based on the integration of online learning using MOOC and face-to-face learning. Specifically, the aim of the study was to identify factors that could influence student acceptance of MOOC in terms of immersion (IM) and intention to use (BIU) based on the HMSAM. Methodology: Quantitative approach through pre-test/post-test control group design was implemented in this study. Simple random sampling was carried out to recruit the study sample comprising 168 undergraduates from a population of 298 students. Pearson correlation analysis, ANOVA and multiple regression analysis were performed on the survey data collected using online questionnaire. Main Findings: Joy, control, perceived usefulness (PU) and curiosity were significantly correlated with $I M$ while $P U$, joy and curiosity were significantly correlated with BIU. Control, PU, joy and curiosity were significant predictors of student acceptance in terms of $I M$ and $B I U .33 \%$ of $I M$ variances and $22 \%$ of $B I U$ variances can be predicted by control, $P U$, joy and curiosity. Applications of this study: This study is useful in educational technology area where it shows that MOOC is a potent platform for blended learning, but its effectiveness relies on appropriate division of learning between online and face-to-face mode. Therefore the study on teaching and learning strategies, techniques and tools are widely open in order to improve the effectiveness of blended learning in the future. Novelty/Originality of this study: The finding suggests that the proportion of learning based on online and face-to-face mode should be carefully apportioned where the effectiveness of MOOC in the blended learning was significantly lower if it was used up to $71 \%$ and the effectiveness will be increased if only $29 \%$ of MOOC was used in the non-blended learning.
\end{abstract}

Keywords Acceptance, Blended Learning, Effectiveness, Institutions of Higher Learning (IHL), Massive Open Online Course (MOOC), Malaysia [Done]

\section{Introduction}

According to Staker and Horn (2012) blended learning is defined as a formal education program where students learn at least part of course materials online, with some of the course instructions being delivered online. Such a learning approach is also accompanied by several elements of student control encompassing time, place, path and pace of learning. Interestingly, some students are supervised at locations far away from their homes. In this regard, while Allen and Seaman (2010) stated that blended learning of a course should be based on a mix of contents delivery where $30 \%$ to $79 \%$ of the learning contents to be delivered through online mode and the rest through face-to-face learning mode, the Malaysia's National e-Learning Policy Document or DePAN (Ministry of Higher Education, 2011) however stipulates that the courses conducted through the blended learning approach should cover at least $30 \%$ of contents, management and e-assessment through the online platform, and the rest is performed face-to-face.

At Universiti Pendidikan Sultan Idris (UPSI), the blended learning approach is implemented using its own platform known as MyGuru. Using Myguru, blended learning is deemed to have been carried out based on several criteria, such as the number of materials uploaded to this platform, including at least one instructional plan, a course plan or a course synopsis; seven or more teaching resources, such as modules, additional course materials, videos or slides notes; three or more online activities, such 
as forum, personal message, wiki, announcement or web seminar; and two or more online assessments, such as online quizzes, assignments, portfolios and journals.

As stated in the Executive Summary of Malaysia Education Blueprint for Higher Education for 2015 to 2025 (Ministry of Education Malaysia, 2015) [Done] that contains 10 shifts, online learning approach is considered as an important platform to transform Malaysia into an international education hub by expanding the access to its educational programs for the world community's lifelong learning through the ninth shift, namely Globalized Online Learning (GOL). To realise this shift, MOE has proposed blended learning as a pedagogical approach that needs to be applied in all Malaysia's Institutions of Higher Learning (IHLs). To initiate this effort, 10 common courses in the IHLS have been converted into Massive Open Online Courses (MOOCs) and implemented on the Open Learning platform. Naturally, such an effort requires the necessary transformation entailing Malaysia's education system to employ MOOCs to help make Malaysia as the first country in the world to lead the MOOC integration of courses at the international level. In this regard, UPSI has been given the responsibility to develop MOOC learning materials for several courses, namely Computer Architecture and Organization (CAO), Blog and Website Development (PBLW), and Special Needs Children (KBK). As of May 2017, the CAO course has attracted 1141 students from around the world. In contrast, PBLW and KBK courses have only recorded 79 and 69 students, respectively.

Since the use of MOOC, the instruction of CAO course has shifted to a new learning approach that is now being fully applied in UPSI. Inevitably, there are certainly many challenges and issues arising from its implementation. For this reason, the researchers carried out this study with the main aim to identify factors that may influence the acceptance of student of the integration of MOOC into the traditional face-to-face learning method and to evaluate the effectiveness of its implementation in the learning process.

\section{Literature Review}

\section{Blended Learning: Malaysia Edu-landscape}

A study entitled Students Perceptions on Blended Learning conducted by Abdul and Aris (2016) involving a group of Sultan Abdul Halim Polytechnic's (POLIMAS) students found that the majority of students knew and were aware about the blended learning concept. Surprisingly, the findings showed that the majority of students viewed the blended learning approach to be less fun, and yet they persisted in using it for their learning activities. Abdul and Aris (2016) suggested one of the reasons for this conflicting finding is that they might have recognised and acknowledged the benefits of the blended learning approach. In the same study, she found that a number of internal and external factors, such as students' attitudes, curiosity, and peer influence, also affected the practice of blended learning among the POLIMAS students.

In another study entitled The Suitability of Blended Learning from The Perspective of Postgraduate Student, conducted by Mohd and Khalid (2016) which focused on the perception and acceptance factors of students found that students viewed blended learning and conventional learning to be equally important that should be implemented in their college. This finding suggests that students view both learning approaches to be equally important, thus underscoring the need to expand the use of blended learning approach for student learning.

Another interesting study was carried out by Mohd (2016) that focused on the impact of blended learning on students' academic performance, autonomy, and student motivation. Specifically, this study compared the differences in the above constructs between two groups of student that used blended learning and conventional learning approach among 116 high school students in the learning of an English subject. Interestingly, she found that there was no significant difference in students' academic performance, but students' autonomy and motivation were significantly higher for those that used the blended learning approach.

\section{Massive Open Online Course (MOOC)}

To date, MOOCs has evolved into several strands, such as cMOOCs, xMOOCs, BOOCs, DOCCs, LOOCs, MOORs, SPOCs, and SMOCs. Such changes have prompted many researchers to examine the challenges and factors that motivate the use of MOOC in the teaching and learning process (Chauhan, 2014). For example, Hew and Cheung (2014) reviewed 25 articles and found three main determinants that encourage instructors to use MOOC as follows: i) the motivational intrigue's sense, ii) the eageress to get personal rewards (egoistic), and iii) the altruism's sense. They also found four key challenges in using MOOC in teaching and learning as follows: (i) the difficulty in evaluating student's work, (ii) the sense of speaking to a vacuum due to the absence of student immediate feedback, (iii) the relatively longer and expensive operations, and iv) the lack of student participation in online forums. More revealingly, they discovered that almost $90 \%$ of students had stopped using blended learning, citing several reasons such as lack of incentives, lack of focus in discussion forums, inadequate previous knowledge about related topics, unpredictable expectations of courses, failure to understand contents, lack of avenues to which students could seek help, and lack of time due to other priorities and commitments.

The above findings are consistent with Alraimi, Zo and Ciganek (2015) research findings based on an extensive 
review of several studies of Breslow et al. (2013), Ho et al. (2014), Jordan (2014) and Kolowich (2014), indicating that only a small percentage of students of less than $10 \%$ would complete online courses on the MOOC platform. Arguably, such findings reflect the success of completion the course was not the best measurement of assessing the MOOC effectiveness (Chauhan, 2014; Ho et al., 2014; Jordan, 2014) [Done]. However, the low percentage of students completing the online courses still calls into question the effectiveness of using $\mathrm{MOOC}$ in learning (Chafkin, 2013; Marcus, 2013). [Done]

\section{Hedonic-Motivation System Adoption Model (HMSAM) \\ Hedonic-Motivation System Adoption Model} (HMSAM), as shown in Fig. 1, is the acceptance model for Hedonic-Motivation System (HMS). It was developed based on the acceptance model proposed by Heijden (2004). In essence, HMS is based on the alternative theory perspective that focuses on learning motivation that contributes to the acceptance in the context of process orientation. In such a case, cognitive absorption (CA) seems more prominent as intrinsic motivation rather than as extrinsic motivation.

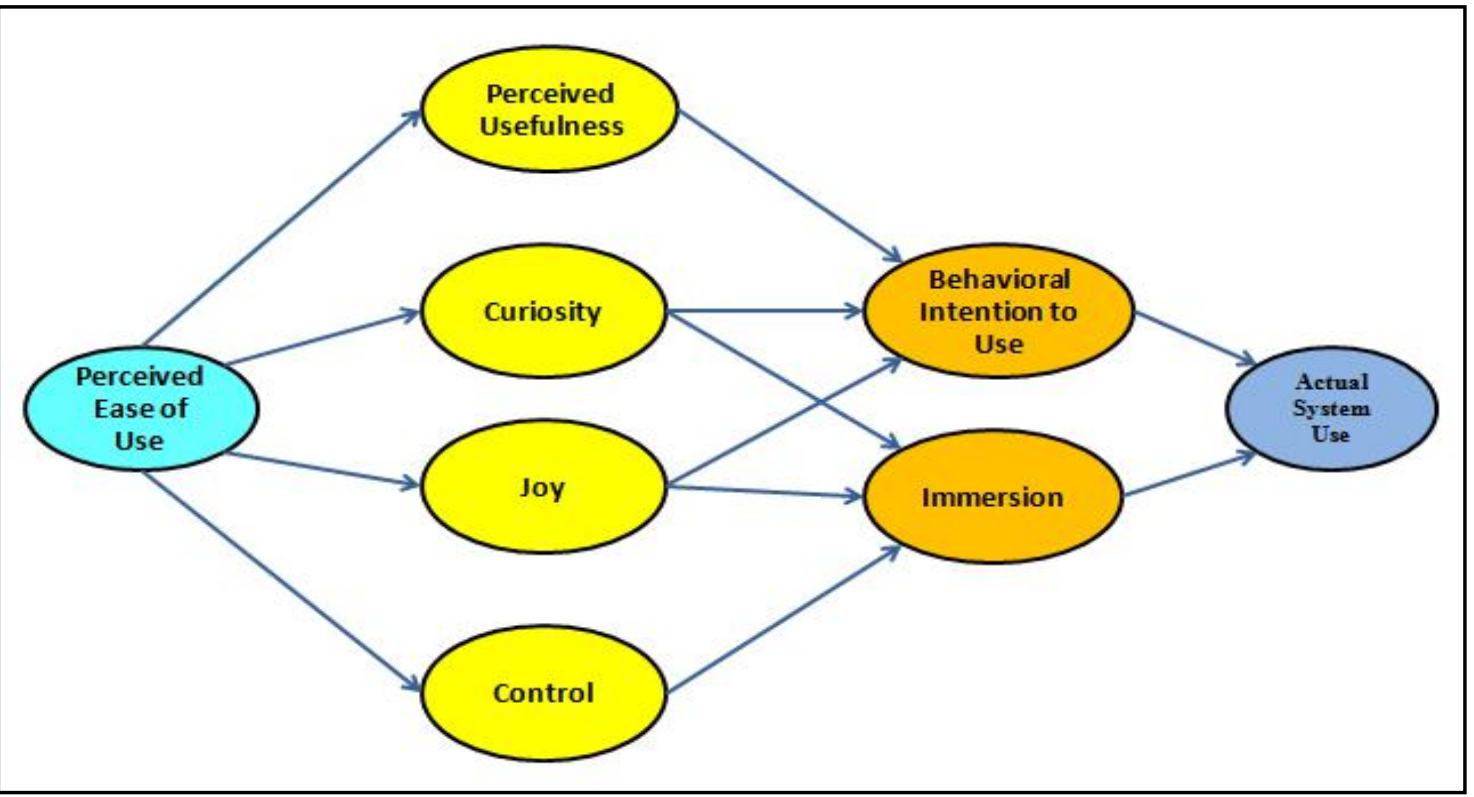

Figure 1. HMSAM

In fact, Heijden's model is a variant of the Technology Acceptance Model (TAM), with the latter being commonly used by researchers to study the adoption of new technologies based on intrinsic motivation. Moreover, TAM is used to describe individual's acceptance level of information systems based on two main factors, namely perceived ease of use (PEOU) and perceived usefulness (PU), which in turn influence users' attitude and behavioural intention to use (BIU) (Davis, Bagozzi, \& Warshaw, 1989).

Premised on the HMSAM, Lowry, Gaskin, Twyman, Hammer and Roberts (2013) further refined Heijden's acceptance model by adding other CA elements, such as perceived usefulness, curiosity, joy, control, focus immersion, and temporal dissociation as key elements of the relationship between PEOU and BIU. In this regard, CA is deemed to be the strongest factor to influence BIU. However, focus immersion and temporal dissociation have been removed from other CA components because of their synchronous effect, making immersion (IM) (in addition to BIU) as another vital factor in the revised model as shown in Fig. 1. Fig. 1 clearly shows that curiosity and joy can affect both $I M$ and BIU, but control can only affect $I M$. Therefore, the combination of intrinsic motivation and flow-based cognitive absorption (CA) serves as the basis of HMSAM to measure the acceptance of actual system use through BIU and IM. 


\section{Methodology}

Simple random sampling was carried out to select the study sample comprising 168 students from a population of 298 students, who were taking CAO course online. The study sample consisted of 23 male students and 59 female students, representing $28 \%$ and $72 \%$ of the respondents, respectively, who were assigned to an experimental group. Meanwhile 33 male students and 53 female students, representing $38 \%$ and $62 \%$ of the respondent, respectively, assigned to a control group. Both of the groups used MOOC with different percentage in their learning process for one semester but they were taught by the same lecturer.

The researchers developed a questionnaire consisting of 10 parts (from Part A to Part J) with 63 items as the main research instrument. Part A contains respondents' demographic information, such as gender, student id number, and educational background. Additionally, this part contains six items eliciting respondents' prior knowledge and their experiences in MOOC. Part B to Part I contain several items adapted from Lowry et al.'s (2013) HMSAM model. Finally, Part J contains 24 items constructed based on Chauhan's MOOC evaluation model (Chauhan, 2014). A pilot study was conducted to test the reliability of the questionnaire involving 86 undergraduates, yielding a Cronbach's Alpha coefficient of 0.87 , which was above the minimum acceptable level. Assisted by research assistant, the respondents were administered with an online questionnaire using Google Form on the final week of the semester.

Bivariate correlation analysis based on Pearson correlation was performed to determine the strength of associations between factors with student acceptance of the integration of MOOC into CAO's traditional face-to-face learning for the CAO course at UPSI. Specifically, Pearson correlation coefficient, $r$, was used to determine the strength of relationships between the dependent variables and independent variables. In this study, the independent variables were factors that could influence student acceptance of MOOC integration into face-to-face learning, namely joy, control, curiosity and perceived usefulness. The dependent variables were immersion (IM) and behavioural intention to use (BIU), which are variables that were derived from the HMSAM model. The coefficient of correlation, $r$, ranges from -1.00 to +1.00 that indicates the strength and direction of the relationship between two variables. Furthermore, analysis of variance (ANOVA) and multiple regression analysis were performed to determine the predictors of student acceptance of the integration of MOOC into face-to-face learning for the CAO course.

In addition, independent sample t-test was performed to analyse the difference in effectiveness of MOOC between the treatment group and the control group. This test helped the researchers to determine whether the difference in effectiveness, if any, between the two groups was significant or not.

\section{Discussion/ Analysis}

Analysis results obtained from the bivariate correlation analysis on treatment group showed that Pearson correlation coefficient, $r$ between perceived usefulness and $I M$ was $\mathrm{r}=.39, \mathrm{p}<.05$; the $r$ between curiosity and $I M$ was $\mathrm{r}=.35, \mathrm{p}<.05$; the $r$ between joy and $I M$ was $\mathrm{r}$ $=.42, \mathrm{p}<.05$ and the $r$ between control and $I M$ was $\mathrm{r}$ $=.41, \mathrm{p}<.05$. The same analysis showed that Pearson correlation coefficient, $r$ between perceived usefulness and $B I U$ was $\mathrm{r}=.39, \mathrm{p}<.05$; the $r$ between curiosity and $B I U$ was $\mathrm{r}=.32, \mathrm{p}<.05$; the $r$ between joy and $B I U$ was $\mathrm{r}$ $=.38, \mathrm{p}<.05$ and the $r$ between control and BIU was $\mathrm{r}$ $=.15, \mathrm{p}>.05$. In order to determine the predictors of student acceptance of the integration of MOOC into face-to-face learning in terms of $I M$ and $B I U$, some of the research findings for the treatment group are shown in Table 1, Table 2 and Table 3.

Table 1. ANOVA analysis on $I M$

\begin{tabular}{ccccccc}
\hline Model & & Sum of Squares & df & Mean Square & F & Sig. \\
\hline \multirow{2}{*}{1} & Regression & 3.866 & 4 & .967 & 9.505 & $.000 \mathrm{~b}$ \\
& Residual & 7.830 & 77 & .102 & & \\
& Total & 11.696 & 81 & & & \\
\hline
\end{tabular}

a.Dependent Variable: Immersion

b.Predictors:(Constant),Usefulness,Control,Curiosity,Joy 
Table 2. Regression coefficient analysis on $I M$

\begin{tabular}{ccccccccc}
\hline \multicolumn{1}{l}{ Model } & \multicolumn{2}{c}{$\begin{array}{c}\text { Unstandardized } \\
\text { Coefficients } \\
\text { Std. Error }\end{array}$} & $\begin{array}{c}\text { Standardized } \\
\text { Coefficients } \\
\text { Beta }\end{array}$ & B & & Sig. & \multicolumn{2}{c}{ Collinearity Statistic } \\
\hline \multirow{4}{*}{1} & (Constant) & .504 & .372 & & 1.354 & & .180 & VIF \\
& Joy & .157 & .097 & .187 & 1.610 & .111 & .647 & 1.545 \\
& Control & .373 & .116 & .320 & 3.220 & .002 & .878 & 1.138 \\
& Curiosity & .084 & .096 & .094 & .847 & .385 & .754 & 1.326 \\
& Usefulness & .170 & .089 & .226 & 1.916 & .059 & .625 & 1.600 \\
\hline
\end{tabular}

a. Dependent Variable: Immersion

Table 3. Variance percentage correlation analysis on $B I U$

\begin{tabular}{ccccc}
\hline Model & $\mathrm{R}$ & $\mathrm{R}$ Square & $\begin{array}{c}\text { Adjusted R } \\
\text { Square }\end{array}$ & $\begin{array}{c}\text { Std. Error of } \\
\text { the Estimate }\end{array}$ \\
\hline 1 & $.463 \mathrm{a}$ & .215 & .174 & .51752 \\
\hline \multicolumn{2}{l}{ a. Predictors: (Constant), Usefulness, Control, Curiosity, Joy }
\end{tabular}

In meanwhile, the findings from independent t-test showed the mean score of MOOC effectiveness of the treatment group was $(\mathrm{M}=2.84, \mathrm{SD}=.51)$, and the mean score of MOOC effectiveness of the control group was (M $=3.03, \mathrm{SD}=.32)$, yielding a difference of $.19(\mathrm{~T}(166)=$ $2.90, \mathrm{p}=.00, \mathrm{p}<.05)$.

The bivariate correlation analysis carried out showed the relationship between perceived usefulness and $I M$ was significant and low. Likewise, the relationship between curiosity and $I M$ was significant and low. In contrast, the relationship between joy and $I M$ was significant and medium and likewise, the relationship between control and $I M$ was significant and medium. Such findings provide no evidence to support the null hypotheses $\mathrm{H}_{0.1-1}$, $\mathrm{H}_{0.1-2}, \mathrm{H}_{0.1-3}$, and $\mathrm{H}_{0.1-4}$. Therefore, the analyses results showed perceived usefulness, curiosity, joy, and control were significantly correlated, albeit weak or moderate in strength, with student acceptance of the integration of MOOC into face-to-face learning of the CAO course. In particular, joy was a dominant factor influencing student acceptance in terms of $I M$, followed by control, perceived usefulness, and curiosity. This particular finding is not consistent with previous findings of studies of HMSAM model, which showed $I M$ was influenced by three out of four factors, namely joy, control and curiosity. Interestingly, analyses based on ANOVA, multiple linear regressions and variance percentage correlation showed that there were four significant predictors of $I M\left(\mathrm{~B}_{1 \text { (joy })}\right.$ $=.16, \mathrm{~B}_{2 \text { (control) }}=.37, \mathrm{~B}_{3 \text { (curiosity) }}=.10, \mathrm{~B}_{4 \text { (usefulness) }}=.17, \mathrm{p}$ $=.18) ;\left(\operatorname{Beta}_{(\text {oy) }}=.19, \operatorname{Beta}_{(\text {control })}=.32, \operatorname{Beta}_{(\text {curiosity })}=.10\right.$, $\mathrm{Beta}_{\text {(usefulness) }}=.23, \mathrm{p}=.180$ ) and $33 \%$ of $I M$ variances can be predicted by control as the most dominant predictor, followed by perceived usefulness, joy and curiosity.

The same bivariate correlation analysis showed that the relationship between perceived usefulness and BIU was significant and low. Likewise, the relationship between curiosity and BIU was significant and low. Similarly, the relationship between joy and $B I U$ was significant and low. Again, such findings provide no evidence to support the null hypotheses $\mathrm{H}_{0.1-5}, \mathrm{H}_{0.1-7}, \mathrm{H}_{0.1-8}$. In contrast, the relationship between control and $B I U$ was not significant and there was no relationship at all. As such, this finding provides no evidence to support research hypothesis $\mathrm{H}_{1.1-6}$. Therefore, the results of correlational analyses showed that perceived usefulness, joy, and curiosity were significantly correlated with student acceptance of the integration of MOOC into face-to-face learning of the CAO course, but their relationships were quite weak. In particular, perceived usefulness was observed to be the most dominant factor, followed by joy and curiosity. The non-relationship between control and BIU is hardly surprising, given that the association between this construct and $B I U$ has been consistently found to be not significant in most studies. Surprisingly, the analyses based on ANOVA, multiple linear regressions and variance percentage correlation showed that there were four significant predictors of $B I U\left(\mathrm{~B}_{1 \text { (joy })}=.25, \mathrm{~B}_{2 \text { (control) }}\right.$ $=.08, \mathrm{~B}_{3 \text { (curiosity) }}=.21, \mathrm{~B}_{4 \text { (usefulness) }}=.24, \mathrm{p}=.29$ ); $\left(\right.$ Beta $_{(\text {ooy })}=.20, \quad B e t a($ control) $)=.05, \quad B e t a($ curiosity) $)=.16$, $\left.B e t a_{\text {(usefulness) }}=.21, \mathrm{p}=.29\right)$ and $22 \%$ of $B I U$ variances can be predicted by joy and perceived usefulness as the most dominant predictors, followed by curiosity and control. However, control had the least predictive power, attested by its very low regression coefficient and Beta values of .08 and .05 , respectively. Effectively, this finding provided the evidence to support null hypothesis $\mathrm{H}_{0.1-6}$, indicating that there was no significant relationship between control and student acceptance in terms of BIU.

In overall, clearly the particular research finding suggests that curiosity and joy can influence student acceptance of MOOC in the blended learning, especially in terms of $I M$ and $B I U$, which is consistent with Heijden's (2004) assertion. Moreover, similar findings indicate that perceived usefulness also can influence both $I M$ and $B I U$, which is not the case for the original HMSAM that suggests such a construct can only affect $B I U$. Accordingly, HMSAM was refined in light of the new findings of this study, as shown in Fig. 2. 


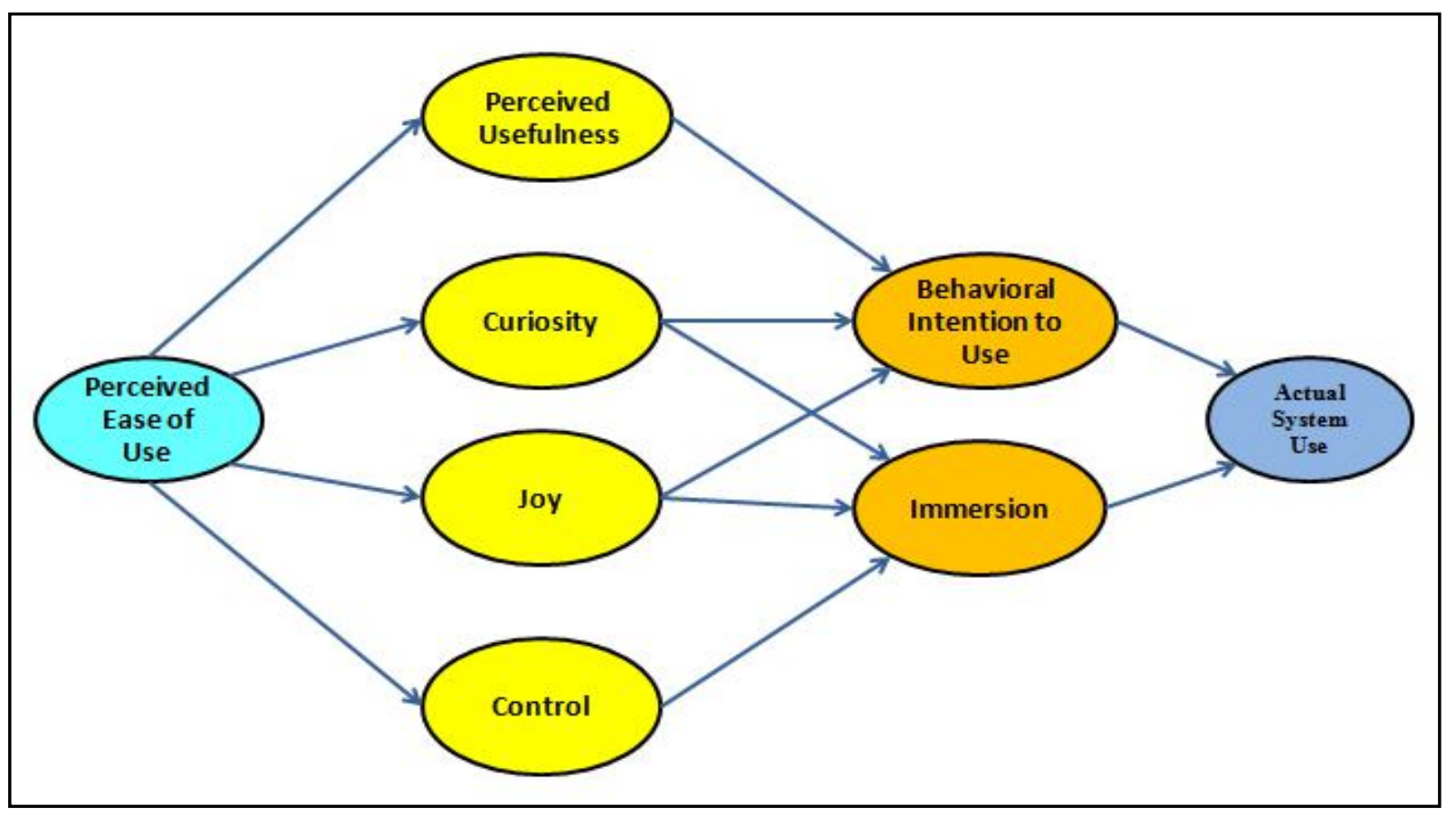

Figure 2. The refined HMSAM

Revealingly, the findings of independent t-test showed that the effectiveness of MOOC was significantly higher than face-to-face learning if the non-blended learning was implemented or only when $29 \%$ of MOOC was carried out. However, increasing the percentage of MOOC in the blended learning up to $71 \%$ was counterproductive, as MOOC effectiveness decreased quitesignificantly. Obviously, these findings reinforce the needs to strike a fine balance between the two types of learning in the blended learning approach. As demonstrated, for effective MOOC, the percentage of face-to-face learning should be more than $29 \%$, ideally ranging from $30 \%$ to $70 \%$, which is naturally governed by the nature of the subject matter. Overall, this study shows that MOOC is a potent platform for blended learning, but its effectiveness relies on appropriate division of learning between online and face-to-face learning.

\section{Conclusions}

The study was carried out to investigate the acceptance factor and the effectiveness of MOOC in the blended learning of CAO course at UPSI. The findings of this study is significant in order to support the $9^{\text {th }}$ shift of Malaysia Education Blueprint for Higher Education for 2015 to 2025 (Ministry of Education Malaysia, 2015), by providing the result of the pioneer execution of MOOC in the blended learning, by one out of 10 selected common courses.

\section{Limitation and Study Forward}

This study is useful in educational technology area where it shows that MOOC is a potent platform for blended learning, but its effectiveness relies on appropriate division of learning between online and face-to-face mode. Therefore the study on teaching and learning strategies, techniques and tools are widely open in order to improve the effectiveness of blended learning in the future.

\section{Acknowledgment}

Author should present list of acknowledgement at the end. Any financial or nonfinancial support for the study should be The researchers wish to thank the Research Management Centre, UPSI for the University Research Grant (2016-0175-109-01) that helped fund the study and to the Ministry of Education, Malaysia that helped fund the MOOC project in 2015. Also special thanks to research assistant Mohamad Farahim bin Mohd Sanimin of his enduring assistance.

\section{REFERENCES}

[1] Abdul, H.F.H., \& Aris, N.S. (2016). Persepsi Pelajar Terhadap Pembelajaran Teradun. Journal of Technical and Vocational Education, 1(2), 53-63. [Done]

[2] Allen, I.E., \& Seaman, J. (2010). Class Differences: Online Education in the United States. Resource document. Babson Survey Research Group. https://files.eric.ed.gov/fulltext/ED529952.pdf. Accessed 15 January 2017.

[3] Alraimi, K.M., Zo, H., \& Ciganek, A.P. (2015). 
Understanding the MOOCs continuance: The role of openness an reputation. Computers \& Education, 80(), 28-38.

[4] Breslow, L., Pritchard, D.E., DeBoer, J., Stump, G.S., Ho, A.D., \& Seaton, D.T. (2013). Studying learning in the worldwide classroom: Research into edX's first MOOC. Research \& Practice in Assessment, 8(), 13-25.

[5] Chafkin, M. (2013). Udacity's Sebastian Thrun, Godfather Of Free Online Education, Changes Course. Resource document

https://www.fastcompany.com/3021473/udacity-sebastianthrun-uphill-climb. Accessed 10 December 2016.

[6] Chauhan, A. (2014). Massive Open Online Course (MOOCs): Emerging Trends in Assessment and Accreditation. Digital Education Review, 25(), 7-18.

[7] Davis, F.D., Bagozzi, R.P., \& Warshaw, P.R. (1989).User Acceptance of Computer Technology: A Comparison of Two Theoretical Models. Management Science, 35(8), 982-1003.

[8] Heijden, H.V.D. (2004). User Acceptance of Hedonic Information Systems. MIS Quarterly, 28(4), 695-704. [Done]

[9] Hew, K.F., \& Cheung, W.S. (2014). Students' and instructors' use of massive open online courses (MOOCs): Motivations and challenges. Educational Research Review, 12()$, 45-58$.

[10] Ho, A.D., Reich, J., Nesterko, S., Seaton, D.T., Mullaney, T., Waldo, J., et al. (2014). HarvardX and MITx: The first year of open online courses. HarvardX and MITx Working Paper 1.

[11] Jordan. K. (2014). Initial trends in enrolment and completion of massive open online courses. The International Review of Research in Open and Distance Learning, 15(1), 133-160. [Done]

[12] Kolowich, S. (2014). The professors who make the MOOCs. Chronicle of Higher Education, 59(28), A20-A23. [Done]

[13] Lowry, P.B., Gaskin, J., Twyman, N., Hammer, B., \& Roberts, T.L. (2013). Proposing the hedonic-motivation system adoption model (HMSAM) to increase understanding of adoption of hedonically motivated systems. Journal of the Association for Information Systems, 14(11), 617-627. [Done]

[14] Marcus, J. (2013). All Hail MOOCs! Just Don't Ask If They Actually Work. Resource document. http://nation.time.com/2013/09/12/all-hail-moocs-just-dont -ask-if-they-actually-work/. Accessed 9 December 2016.

[15] Ministry of Education. (2015). Executive Summary of Malaysia Education Blueprint for Higher Education 2015-2025. Resource document. Kementerian Pendidikan Malaysia, Putrajaya. https://www.um.edu.my/docs/default-source/about-um do cument/media-centre/um-magazine/4-executive-summarypppm-2015-2025.pdf?sfvrsn=4. Accessed 15 January 2017.

[16] Ministry of Higher Education. (2011). National e-Learning Policy (DePAN). Resource document. Kementerian Pengajian Tinggi, Malaysia https://smart2.ums.edu.my/pluginfile.php/2/course/section/ 2/dasar_e- pembelajaran_negara_depan.pdf. Accessed 20 December 2016. [Done]

[17] Mohd, A.S.K. (2016). The effects of blended learning in the teaching of English through short story among secondary school students. Tanjong Malim: Universiti Pendidikan Sultan Idris.

[18] Mohd, K.N.N., \& Khalid, F. (2016). Kesesuaian Pembelajaran Teradun Dari Sudut Pandangan Pelajar Pascasiswazah. International Conference on Education for Sustainable Regional Development 2016. Resource document.

http://icerd2016.conference.upi.edu/wpcontent/uploads/site s/13/2016/10/93. Accessed 15 February 2017.

[19] Staker, H., \& Horn, M.B. (2012). Classifying K-12 Blended Learning. Resource document. Innosight Institute, Harvard. https://files.eric.ed.gov/fulltext/ED535180.pdf. Accessed 10 November 2016. [Done] 